\title{
Continuation of Liraglutide During Fasting Is Not Associated with Hypoglycaemia
}

\author{
Rosalie Koot ${ }^{1}$, Marcel van Borren², Hans de Boer ${ }^{1}$ \\ ${ }^{1}$ Department of Internal Medicine, Rijnstate Hospital, Arnhem, The Netherlands \\ ${ }^{2}$ Department of Clinical Chemistry, Rijnstate Hospital, Arnhem, The Netherlands
}

Received: $14 / 08 / 2017$

Accepted: $19 / 08 / 2017$

Published: $26 / 10 / 2017$

How to cite this article: Koot R, van Borren M, de Boer H. Continuation of liraglutide during fasting is not associated with hypogycaemia. EJCRIM 2017;4: doi:10.12890/2017_000712

Conflicts of Interests: The Authors declare that there are no competing interests.

This article is licensed under a Commons Attribution Non-Commercial 4.0 License

\section{ABSTRACT}

Liraglutide, a glucagon-like peptide-1 (GLP-1) analog, is increasingly used in obese patients with type 2 diabetes mellitus (T2DM) in doses of up to $3.0 \mathrm{mg} /$ day because of its attractive pharmacological profile. It is currently not known how to proceed with this medication during fasting for surgery. Discontinuation is likely to result in hyperglycaemia, while continuation might lead to hypoglycaemia, but, in view of its mode of action, continuation of GLP-1 analogs is likely to be safe. However, as evidence-based guidelines on GLP-1 management during perioperative fasting are not available, the safety of either policy needs to be confirmed on an individual basis. We therefore decided to perform a preoperative assessment of the glucose response to fasting during continuation of GLP-1 before giving a recommendation in individual cases. So far, 12 severely obese T2DM patients scheduled for bariatric surgery have been evaluated preoperatively by measuring glucose and insulin levels during a 32-hour fast with continuation of liraglutide. Hypoglycaemia was not observed. This suggests that liraglutide in doses of up to $3.0 \mathrm{mg}$ can be safely continued during surgery without risking hypoglycaemia.

\section{LEARNING POINTS}

- Evidence-based guidelines on how to proceed with GLP-1 analogs during perioperative fasting are currently not available.

- Our observations suggest that liraglutide in doses of up to $3.0 \mathrm{mg} /$ day can be safely continued during perioperative fasting for 32 hours.

- Further evaluation is needed for fasting periods longer than 32 hours.

\section{KEYWORDS}

Liraglutide, obesity, GLP-1 analog, fasting, hypoglycaemia

\section{BACKGROUND}

Liraglutide, a glucagon-like peptide-1 (GLP-1) analog, is increasingly used in obese patients with type 2 diabetes mellitus (T2DM) because of its attractive pharmacological profile. It improves glycaemic control, induces weight loss and is associated with a low risk of hypoglycaemia ${ }^{[1]}$. Liraglutide is currently used for the treatment of T2DM in doses of up to $1.8 \mathrm{mg} / \mathrm{day}$ and for the treatment of obesity in doses of up to 3.0 $\mathrm{mg} / \mathrm{day}^{[2]}$. As bariatric surgery is a major specialty in our institution, severely obese T2DM patients treated with liraglutide up to $3.0 \mathrm{mg} / \mathrm{day}$ are frequently referred to the department of internal medicine for advice on how to proceed with this medication during surgery. Should it be discontinued and risk hyperglycaemia requiring ad hoc insulin treatment or can it be safely continued and maintain optimal glycaemic control? As evidence-based guidelines on GLP-1 treatment during perioperative fasting are not available, we felt that preoperative assessment of the glucose response to fasting was warranted before giving perioperative advice in individual cases. 
This information was obtained by preoperative assessment of the glucose and insulin response during a 32-hour fast while continuing liraglutide. The background to this assessment was explained to all patients, and all gave their informed consent prior to testing.

\section{CASE PRESENTATION}

So far, we have evaluated 12 severely obese T2DM patients scheduled for bariatric surgery. They were treated with a combination of metformin at a mean \pm SE daily dose of $2000 \pm 296 \mathrm{mg}$, and liraglutide once or twice daily with a mean \pm SE daily dose of $2.5 \pm 0.2 \mathrm{mg}$ (range: 1.8-3.0 mg/day). The mean age was $53 \pm 2.5$ years, body mass index (BMI) was $37.8 \pm 2.0 \mathrm{~kg} / \mathrm{m} 2$, and $\mathrm{HbA} 1 \mathrm{c}$ was $54.8 \pm 3.2 \mathrm{mmol} / \mathrm{mol}$. Measurement of plasma glucose (P800, Roche) and insulin (Immulite XP2000, Siemens) levels every 2-3 hours was started at 12.00 h on day 1 while patients continued their usual diet. Fasting for a period of 32 hours was started at $24.00 \mathrm{~h}$ on day 1 and continued until 08.00 $\mathrm{h}$ on day 3. Drinking of water was allowed during fasting. On day 3 , all patients resumed their usual diet at $08.00 \mathrm{~h}$. The observation period ended at $12.00 \mathrm{~h}$. Hypoglycaemia was defined as a plasma glucose level $<3.5 \mathrm{mmol} / \mathrm{l}$.

The results of the preoperative evaluation procedure are shown in Fig. 1. The mean glucose and insulin responses are shown as black dots and the individual data as open circles. During the 32-hour fast, mean plasma glucose levels gradually declined from $7.3 \pm 0.7 \mathrm{mmol} / \mathrm{l}$ to a minimum of $5.7 \pm 0.3 \mathrm{mmol} / \mathrm{l}$ in the first 24 hours and then increased slightly to $6.4 \pm 0.6 \mathrm{mmol} / \mathrm{l}$ at 32 hours. Insulin levels decreased from $22.9 \pm 3.4$ to $8.6 \pm 1.8 \mathrm{mU} / \mathrm{l}$ and then to $8.3 \pm 2.1 \mathrm{mU} / \mathrm{l}$. Nadir glucose levels of individual patients ranged from 4.0 to $6.8 \mathrm{mmol} / \mathrm{l}$. Hypoglycaemia was not observed.

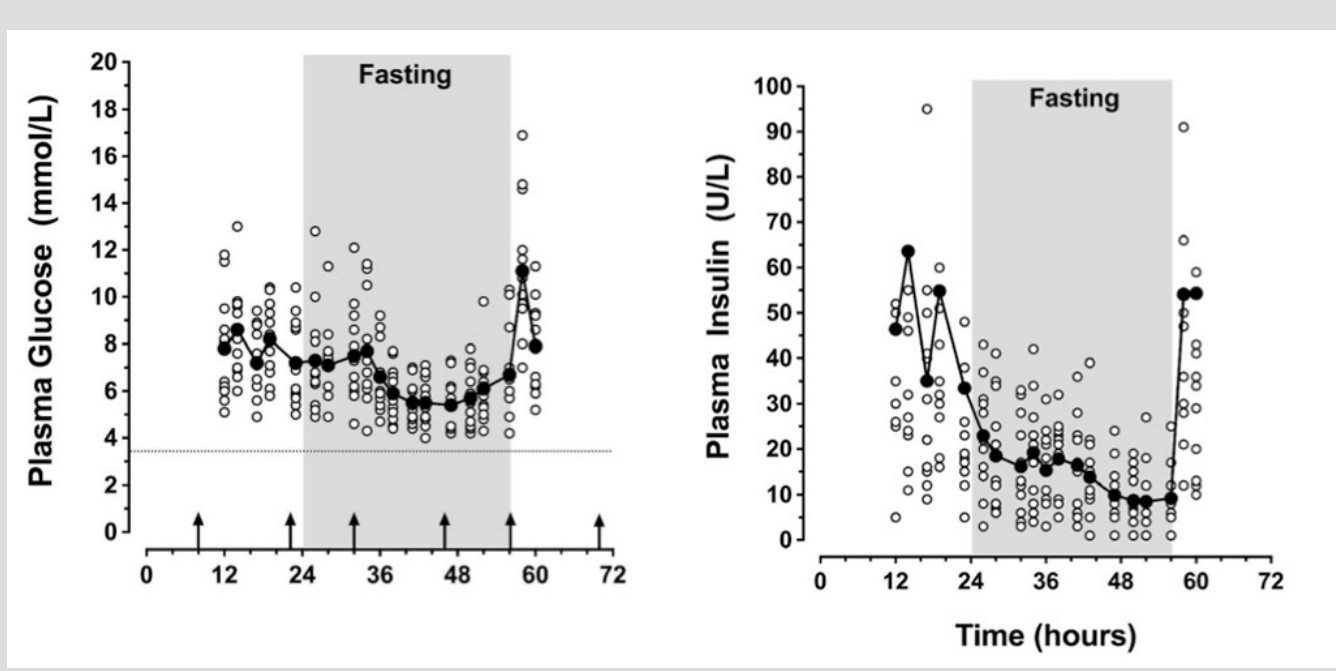

Figure 1. Glucose and insulin responses in patients with type 2 diabetes during fasting. The mean responses are shown as black dots, individual values as open circles. Grey area: 32-hour fasting period. Arrows: timing of liraglutide injections

\section{OUTCOME}

So far, gastric bypass surgery has been performed in 10 patients. They continued liraglutide at the same dose as used preoperatively, and none developed hypoglycaemia. The lowest perioperative glucose level was $5.7 \mathrm{mmol} / \mathrm{l}$, while the highest level was $19.6 \mathrm{mmol} / \mathrm{l}$.

\section{DISCUSSION}

These preliminary observations suggest that liraglutide in doses of up to $3.0 \mathrm{mg} /$ day can be safely continued during surgery without risking hypoglycaemia. The findings are in agreement with the currently known mode of action of GLP-1 agonists. As the ability of GLP-1 agonists to promote insulin secretion depends on the presence of elevated blood glucose levels, their activity ceases when blood glucose levels decline $^{[1]}$. It has been shown that healthy human subjects treated with pharmacological intravenous doses of GLP-1 after an overnight fast do not develop hypoglycaemia ${ }^{[2]}$. GLP-1's glucose dependence was also nicely demonstrated in euglycaemic clamp studies in fasting healthy subjects. Continuous infusion of the GLP-1 agonist exenatide ceased to stimulate insulin secretion when plasma glucose levels dropped to $4.0 \mathrm{mmol} / \mathrm{l}$ or less ${ }^{[3]}$. 
A recent study of eight healthy men continuously infused with either a pharmacological dose of native GLP-1 or placebo during a 48-hour fast demonstrated that glucose levels declined in a similar manner to a mean of $3.7 \mathrm{mmol} / \mathrm{l}$, with parallel declines in insulin and C-peptide levels to a similar extent in both groups ${ }^{[4]}$. The low risk of hypoglycaemia with high-dose liraglutide was also demonstrated in a study of 93 non-fasting, non-diabetic obese subjects treated with liraglutide $3.0 \mathrm{mg} /$ day as weight-lowering pharmacotherapy ${ }^{[5]}$. This observation was recently confirmed in a large 56-week placebo-controlled trial evaluating the efficacy and safety of liraglutide $3.0 \mathrm{mg} / \mathrm{day}$ in non-diabetic obese men and women: spontaneous hypoglycaemia was reported by 32 of 2481 patients (1.3\%) in the liraglutide group and by 13 of 1242 patients (1.0\%) in the placebo group ${ }^{[6]}$.

To our knowledge, the present report is the first to describe the safety of GLP-1 treatment in fasting T2DM patients. However, the number of observations is still too small to generalize these findings. Other limitations are the relatively short fasting period of $32 \mathrm{hours}$, and the fact that only severely obese patients were included. It is not known what will happen if the post-operative fasting period has to be extended beyond 32 hours, or what the response will be in normal weight and overweight patients with T2DM. Further evaluation is also needed to examine whether the anti-hyperglycemic effects of GLP-1 analogs are sufficiently strong to prevent perioperative, stress-induced hyperglycaemia. In view of the increasing use of GLP-1 analogs, we recommend that research is extended so that solid evidence-based instructions can be developed.

\section{REFERENCES}

1. Meloni AR, De Young MD, Lowe C, Parkes DG. GLP-1 receptor activated insulin secretion from pancreatic $\beta$-cells: mechanism and glucose dependence. Diab Obes Metab 2012;15:15-27.

2. Qualmann C, Nauck MA, Holst JJ, Orskov C, Creutzveldt W. Insulinotropic actions of intravenous glucagon-like peptide-1 (GLP-1) in the fasting state in healthy subjects. Acto Diabetol 1995;32:13-16.

3. Degn KB, Brock B, Juhl CB, Djurhuus CB, Grubert J, Kim D, et al. Effect of intravenous infusion of exenatide (synthetic exendin-4) on glucose dependent insulin secretion and counterregulation during hypoglycemia. Diabetes 2004;53:2397-2403.

4. Lerche S, Soendergaard L, Rungby J, Moeller N, Holst JJ, Schmitz OE, et al. No increased risk of hypoglycaemic episodes during 48 h of subcutaneous glucagon-like-peptide-1 administration in fasting healthy subjects. Clin Endocrinol (Oxf) 2009;71:500-506.

5. Astrup A, Carraro R, Finer N, Harper A, Kunesova M, Lean MEJ, et al. Safety, tolerability and sustained weight loss over 2 years with the once-daily human GLP-1 analog, liragutide. Int J Obes 2011;36:843-854.

6. Pi-Sunyer X, Astrup A, Fujioka KA, et al. Randomized, controlled trial of 3.0 mg liraglutide in weight management. N Engl J Med 2015;373:11-22. 